\title{
Identification of Bacterial Glycosidases in Rat Cecal Contents
}

\author{
ROBERTO PRIZONT and NANCY KONIGSBERG
}

\begin{abstract}
Cecal contents of conventional and germfree rats were examined for glycosidases which may have a role in degrading glycoprotein oligosaccharides. Utilizing p-nitrophenylglycosides as substrates, we identified glycosidases in bacteria-free supernatants from cecal contents which act on $\beta$-linkages. These cecal glycosidases appear to be of bacterial origin since: (1) direct comparisons of the enzymes in similar contents from germfree rats showed negligible activities; (2) most of the glycosidase levels in bacterial extracts were at least as high as those of soluble supernatants; and (3) disk gel electrophoresis of contents and bacterial extracts revealed in both preparations a $\beta-\mathrm{N}$-acetylglucosaminidase band with similar $\mathrm{R}_{f}$ s. Also, the blood group $B$ antigenicity of germfree cecal glycoproteins was greatly decreased by conventional cecal contents. These findings indicate that $\beta$ galactosidase and $\beta-\mathrm{N}$-acetylgalactosaminidase in cecal contents are bacterial in origin, and they may have a role in the bacterial catabolism of intestinal glycoproteins.
\end{abstract}

The cells of the small intestine are bathed by a mucilaginous material which possesses properties found in secretory mucins (1). The cell membrane beneath this mucin layer contains a "glycocalyx" which has histochemical and biochemical characteristics of membrane glycoproteins (2-4). After the intestinal cells complete their life cycle in the villi, they are shed into the lumen, and a mixture of secretory and membrane glycoproteins is carried down to the lower levels of the intestinal tract (5). In germfree animals, these undegraded glycoproteins accumulate in the cecum and large bowel. Thus, the feces of these animals contain large quantities of nondialyzable glycoproteins, as shown by the pioneer work of Hoskins (6). Incubation of feces from conventional rats with feces of germfree

\footnotetext{
Manuscript received August 19, 1980; revised manuscript received January 29, 1981; accepted January 29, 1981.

From the Department of Internal Medicine, Gastrointestinal Research Division, University of Michigan, Ann Arbor, Michigan 48109.

Dr. R. Prizont's present address is: Veterans Administration Medical Center, Albuquerque, New Mexico 87108.

Address for reprint requests: Dr. Roberto Prizont, VA Medical Center, Albuquerque, New Mexico 87108.
}

rats lowers the carbohydrate content of the oligosaccharide chains (6). In further experiments, Hoskins found in feces of conventional rats and human subjects bacterial enzymes degrading blood group substances (8). These A, B, and $\mathrm{H}$ blood groupdegrading enzymes act only on the $\alpha$-terminal linkage of the oligosaccharide chain removing $N$-acetylgalactosamine, D-galactose and L-fucose, respectively (9).

The biochemical analysis of ovine colonic mucins (10) and intestinal brush border glycoproteins (11) reveals a complex oligosaccharide chain which contains sugars other than the ones which confer blood group reactivity to the molecule. D- $N$-acetylglucosamine, mannose, and sialic acid are common parts of the carbohydrate structure, as well as $\mathrm{N}$-acetylgalactosamine and D-galactose in $\beta$-glycosidic linkage. Thus, in order to degrade the oligosaccharide chain, enteric bacteria would have to produce a multiple system of glycosidases. Isolated $\beta$-glycosidases have already been identified in pure cultures of enteric bacteria (12), and our preliminary experiments have shown several of these enzymes in rat cecal content (13). The present study was conceived to: (1) identify different forms of glycosi- 
dases in rat cecal content and (2) determine whether they might derive from the host or the bacterial flora.

\section{MATERIALS AND METHODS}

The $\beta$ anomeric forms of $p$-nitrophenyl derivatives of $\mathrm{N}$-acetylglucosamine, $\mathrm{N}$-acetylgalactosamine, and D-galactose were obtained from Sigma Chemical Co. (Saint Louis, Missouri). Male albino Sprague-Dawley rats (Charles River, Willmington, Massachusetts) weighing 200-300g were kept in conventional cages and fed a chow laboratory diet and drinking water ad libitum. Germfree rats purchased from Charles River Laboratories or the University of Wisconsin were maintained in vinyl aseptic isolators. These animals were routinely monitored aerobically and anaerobically for bacterial sterility.

Collection and Processing of Cecal Samples. After an overnight fast, conventional and germfree rats were lightly anesthetized under ether and sacrificed by decapitation. All further experiments were carried out at $0-4^{\circ} \mathrm{C}$ in a cold room. After separation of the cecum, the contents were collected in centrifuge tubes, weighed, diluted in cold $0.9 \% \mathrm{NaCl}$, and centrifuged at $500 \mathrm{~g}$ for 15 minutes for the purpose of removing debris. Supernatants were then recentrifuged for another 30 minutes at $15,000 \mathrm{~g}$ in order to obtain a clear supernatant from all animals and a "bacterial pellet" from conventional rats. Mason (14) and Allison (15) have shown in feces and ruminal contents that this system is effective in separating bacteria from other soluble elements. These "bacteria-free supernatants" were used for enzyme analysis. In subsequent experiments bacterial pellets were thoroughly washed with $\mathrm{NaCl} 0.9 \%$, resuspended in the $\mathrm{NaCl}$ solution, and disrupted by a $15-\mathrm{sec}$ sonication on an ice bath. The suspensions were then cleared of gross bacterial components by a $15,000 \mathrm{~g}$ centrifugation and the resulting clear supernatants were labeled as "bacterial extracts" and assayed for glycosidase activities with $p$-nitrophenylglycosides.

Glycosidase Assays. Cecal supernatant solutions of contents and bacterial pellets were incubated with the $\beta$ anomeric forms of $p$-nitrophenylglycosides and assayed with $0.05 \mathrm{M}$ citrate buffer at $30^{\circ} \mathrm{C}$ at the optimum predetermined $\mathrm{pH}$ according to the method described by Bahl et al (16). In our laboratory and with these artificial substrates, the optimum $\mathrm{pH}$ achieved by cecal glycosidases was 5.5 , which corresponds closely with the optimum $\mathrm{pH}$ of 5.5-6.5 found by Hoskins et al for fecal blood group-degrading enzymes (9). After 15-30 min of incubation, sodium carbonate was added, and the yellow color produced by the released $p$-nitrophenol was measured in a Beckman spectrophotometer at $420 \mathrm{~nm}$. Sample and substrate controls were also read, so that appropriate corrections could be made for yellow color of the enzyme preparation itself or any spontaneous hydrolysis of the substrate. A unit of enzyme activity is defined as the amount of enzyme that releases one micromole of $p$ nitrophenol per minute. Specific activity was expressed as micromoles of $p$-nitrophenol released per minute per milligram of protein. The protein content was determined by the method of Lowry et al (17), using bovine serum albumin as protein standard.

The action of blood group-degrading glycosidases was assessed by the loss of blood group reactivity of germfree glycoproteins. Glycosidases from bacterial-free supernatant of conventional rats were partially purified by adding to the samples solid ammonium sulfate as to achieve a $65 \%$ saturation of the salt. After several hours equilibration at $0-4^{\circ} \mathrm{C}$, samples were centrifuged at $30,000 \mathrm{~g}$. Pellets were resuspended in water and dialyzed against distilled water. For the assay of the blood group B degrading enzyme, partially purified bacterial-free supernatants were added to tubes containing $1 \%$ of crude, lyophilized germfree glycoproteins in a total volume of $200 \mu \mathrm{l}$. After incubation at $30^{\circ} \mathrm{C}$ for $0,1,2,4$, and $24 \mathrm{hr}$, the reaction was stopped by placing the tubes in a boiling water bath for $2 \mathrm{~min}$. Germfree glycoproteins added to distilled water were also incubated for the same intervals of time to evaluate the spontaneous degradation of the natural substrate. The blood group titer of the germfree glycoproteins was determined in duplicate by hemagglutination inhibition. Thereafter, each incubated sample $(0.05$ $\mathrm{ml}$ ) was serially diluted in $0.05 \mathrm{ml}$ of saline. Two hemagglutinating units of B antisera (American Hospital Corporation, Miami, Florida) contained in $0.05 \mathrm{ml}$ of saline were then added, followed $2 \mathrm{hr}$ later by $0.05 \mathrm{ml}$ of $1 \%$ saline suspensions of washed $B$ erythrocytes according to the method described by Bendick (18). The highest dilution of antigen cecal glycoprotein that inhibited hemagglutination was defined as the antigen titer.

Bacteria-free supernatants and bacterial extracts of cecal contents from conventional rats were submitted to discontinuous gel electrophoresis on $7.5 \%$ gels for $4 \mathrm{hr}$. Approximately $100-200 \mu \mathrm{g}$ of protein were applied to each gel. To identify protein bands, gels were stained with Coomassie blue using the staining protocol of Maizel (19), while destaining of the unbound protein was accomplished with $10 \%$ acetic acid. For determination of enzymatic bands, bacteria-free supernatants and bacterial extracts were run on parallel gels and cut in 1-mm slices. Each sliced gel was then incubated in a small volume of pH 5.5 buffer containing the $p$-nitrophenylglycoside substrate and examined for yellow color at $\mathbf{4 2 0} \mathrm{mm}$ after an overnight incubation at $30^{\circ} \mathrm{C}$.

\section{RESULTS}

Bacteria-free supernatants of conventional cecal contents revealed high activities of glycosidases which act upon $\beta$-linkages, namely; $\beta$ - $N$-acetylglucosaminidase, $\beta-N$-acetylgalactosaminidase, and $\beta$ galactosidase (Figure 1). Contrary to conventional cecum, cecal contents of germfree rats contained negligible glycosidase activities.

To determine if activities of $\beta$-glycosidases were largely extra or intracellular, bacterial extracts obtained from conventional cecal contents were tested for the presence of glycosidases. Activities of $\beta-N$ acetylglucosaminidase, $\beta$-galactosidase, and $\beta-N$ acetylgalactosaminidase in bacterial extracts were 


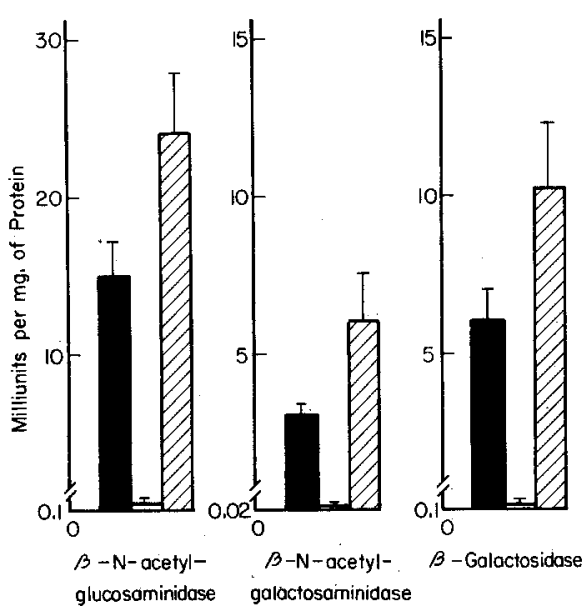

Fig 1. Specific activities of $\beta$-glycosidases in germfree cecal contents (4) $\square$; bacteria free supernatants from conventional cecum (6) 慻; and bacterial extracts from conventional cecum (6) . Bars represent mean \pm standard error of each group.

1.5- to 2-fold higher than activities of similar enzymes from bacteria-free supernatants (Figure 1).

Crude bacteria-free supernatants and bacterial extracts from two conventional rats, containing $\beta$ $N$-acetylglucosaminidase, were run simultaneously on acrylamide gels. A glycosidase band with an $R_{f}$ of $0.38-0.39$ was identified in both preparations. These enzyme bands coincided with similar protein bands found in both preparations. A second $\beta-N$ acetylglucosaminidase band with an $R_{f}$ of 0.54 was only found in bacterial extracts.

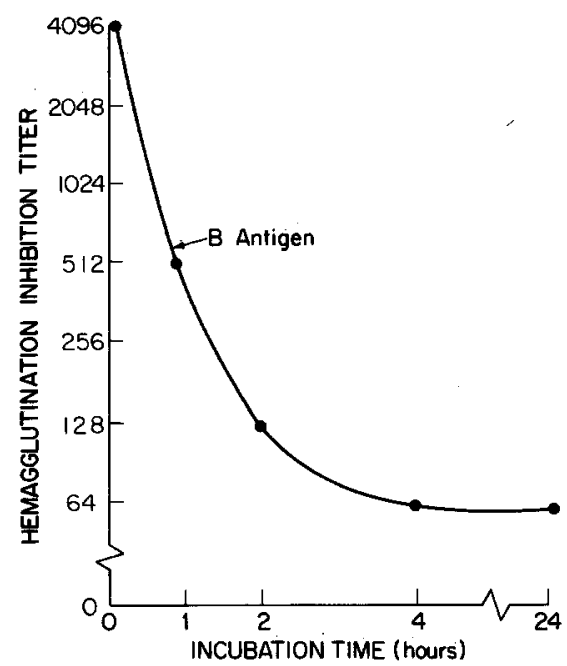

Fig 2. Loss of blood group B antigenicity of cecal glycoprotein from germfree rats after incubation with partially purified bacteria-free supernatants from conventional cecal contents. The hemagglutination inhibition titer of the ordinate represent the exponential dilution of the antigen cecal glycoprotein.
After incubation with partially purified bacteriafree supernatants, the blood group B antigenicity of cecal glycoproteins from germfree rats was markedly lowered. As shown in Figure 2, the hemagglutination inhibition titer revealed a continuous decrease in the blood group B antigen which reached a maximum of 64-fold after $4 \mathrm{hr}$ of incubation. Conversely, germfree cecal glycoprotein had minimal or no change in the blood group reactivity after incubation with distilled water for periods up to $24 \mathrm{hr}$.

\section{DISCUSSION}

The present data revealed high activities of glycosidases which act on $\beta$-linkages in cecal contents of conventional rats. The negligible activities of cecal glycosidases found in germfree rats suggest that these degrading enzymes largely derive from the intestinal microflora. This observation agrees with previous findings that glycosidases from intestinal mucosal homogenates and intestinal cell lysosomes show either none or very low activity against colonic glycoproteins (20). Further evidence of the bacterial origin of these enzymes was suggested by: (1) the elevated glycosidase levels found in bacterial extracts and (2) the identical electrophoretic bands of $\beta-N$-acetylglucosaminidase in both bacterial extracts and bacteria-free supernatants.

The high recovery of enzymes from bacterial flora extracts suggest that glycosidases which act on $\beta$-linkages may be found both extra- and intracellularly. Contrary to the blood group-degrading enzymes (9), the glycosidase activities were high after disruption of bacteria. The second $\beta-N$-acetylglucosaminidase electrophoretic band from bacterial extracts indicates that this second $\beta-N$-acetylglucosaminidase is an exclusive intracellular enzyme. This $\beta$-glycosidase has been previously found intracellularly in enteric bacteria. Hence, Yem and $\mathrm{Wa}(21)$ purified a $\beta-N$-acetylglucosaminidase from cytoplasm of $E$. coli. Our finding of an intracellular $\beta-N$-acetylglucosaminidase could explain the high glycosidase levels recovered from the sonicated bacterial pellets.

The authors recognize that merely because glycosidases split off artificial substrates it does not necessarily mean they will act on natural glycoproteins. A number of glycosidases produced by enteric bacteria with activity on artificial substrates have been shown not to degrade natural glycoproteins. This is true for several blood group-destroying enzymes, as reported for $\mathrm{H}$-destroying $\alpha$-fucosidase in Clostridium perfringens (22), and B-destroying $\alpha-$ 
galactosidase in human feces (9). However, the $\beta$ linkage degrading glycosidases isolated so far from enteric bacteria, similar to those described in this study, have proven to be active against both artificial and natural substrates. Thus, in Clostridium perfringens, an anaerobe often found in feces, McGuire et al isolated a $\beta-N$-acetylglucosaminidase with degrading ability on the $p$-nitrophenylglycoside and submaxillary mucin (23). The same glycosidase, obtained from Escherichia coli, acted on glycopeptides as well as on artificial glycosides (20). Similar degrading properties were found in a $\beta$ galactosidase isolated from Clostridium perfringens (23).

In addition to the previous findings, our study corroborates the observations of Hoskins that the conventional colonic content possesses blood group-degrading ability (6). In this study, cultures of fecal bacteria degraded the A antigen of germfree rat fecal glycoproteins. Subsequently, the substrate employed for assays of blood-degrading enzymes were saliva and hog gastric mucins (7-9). In our study, germfree cecal glycoprotein was used to assess the loss of blood group B antigenicity, rather than hog gastric mucin, since this would be the natural substrate on which blood group-degrading enzymes would act.

Thus, this study suggests that intestinal glycoproteins accumulated in the cecum could be hydrolyzed by a system of multiple degrading glycosidases that act upon both $\alpha$ and $\beta$ linkages of the oligosaccharide chains. The sugars released from the oligosaccharide chains by these glycosidases may be utilized as carbon sources for bacterial growth. They could be metabolized by the bacteria and transferred into organic acids and carbon dioxide (24). As postulated by Hoskins for fecal blood group-degrading enzymes (9), those bacteria which produce multiple glycosidases could definitely be suited for the hydrolysis of complex intestinal glycoproteins. The utilization of carbohydrates could selectively enable the growth of certain bacteria in the colonic environment, thereby becoming independent of dietary sources for nutrients. This biological advantage might explain the large ecological variations found at different levels of the gastrointestinal tract and the predilection of particular bacterial species, such as anaerobes, for large bowel contents.

\section{REFERENCES}

1. Spiro R: Glycoproteins: Their biochemistry, biology and role in human disease. $\mathrm{N}$ Engl J Med 281:991-1056, 1969

2. Gottschalk A: In Glycoproteins: Their Composition, Structure and Function, Vol 5, A Gottschalk, (ed). Publ. Co., New York, Elsevier, 1972, pp 24-28

3. Ito S: Structure and function of the glycocalyx. Fed Proc 28:12-25, 1969

4. Neutra M, Leblond CP: Synthesis of the carbohydrate of mucus in the golgi complex as shown by electron microscope radioautography of goblet cells from rats injected with glucose- ${ }^{3}$ H. J Cell Biol 30:119-136, 1966

5. Alpers DH, Kinzie JL: Regulation of small intestinal protein metabolism. Gastroenterology 64:471-496, 1973

6. Hoskins LC, Zamcheck N: Bacterial degradation of gastrointestinal mucins. I. Comparison of mucus constituents in the stools of germ-free and conventional rats. Gastroenterology $54: 210-217$

7. Hoskins LC: Bacterial degradation of gastrointestinal mucins. II Bacterial origin of fecal ABH (O) blood group antigen-destroying enzymes. Gastroenterology 54:218-224, 1968

8. Hoskins LC: Ecological studies of intestinal bacteria. Relation between the specificity of fecal ABO blood group antigen-degrading enzymes from enteric bacteria and the ABO blood group of the human host. J Clin Invest 48:664673,1969

9. Hoskins LC, Boulding ET: Degradation of blood group antigens in human colon ecosystems. 1 . In vitro production of ABH blood group degrading enzymes by enteric bacteria. J Clin Invest 57:63-73, 1976

10. Drapor P, Kent PW: Biosynthesis of intestinal mucins. Biochem J 86:348-254, 1963

11. Kim SY, Perdomo JM: Membrane glycoproteins of the rat small intestine. Chemical composition of membrane glycoproteins. Biochem Biophys Acta 343:111-124, 1974

12. Hawksworth G, Drasar BS, Hill MJ: Intestinal bacteria and the hydrolysis of glycosidic bonds. Med Microbiol 4:451459, 1971

13. Prizont R, Konigsberg N, Aminoff D: Glycosidase activity in the rat cecal content. Gastroenterology 70:A-928, 1976

14. Mason VC: Some observations on the distribution and origin of nitrogen in sheep feces. J Agric Sci 73:99-111, 1969

15. Allison MJ, Bucklin JA, Robinson IM: Importance of the isovalerate carboxylation pathway of leucine biosynthesis in the rumen. Appl Microbiol 14:807-814, 1966

16. Bahl OP, Agrawal KML: Glycosidases of Phaseolus vulgaris. 1. Isolation and characterization of $\beta-N$-acetylglucosaminidase. J Biol Chem 243:98-111, 1968

17. Lowry $\mathrm{OH}$, Rosebrough NJ, Farr AL, and Randall RJ: Protein measurement with the Folin phenol reagent. J Biol Chem 193:265-275, 1951

18. Bendick A, Debat EA, Bezer AE: İmmunochemical studies on blood groups. V. Further characterization of blood group $A$ and $O$ substances from individual hog stomach. J Am Chem Soc 69:2163-2167, 1947

19. Maizel JV: Polyacrylamide gel electrophoresis of viral proteins. In Methods in Virology, K Maramorosch, H Kaprowski (eds). New York, Academic Press, 1971, pp 179-246

20. Hsu L, and Tappel AL: Lysosomal enzymes and mucopolysaccinarides in the gastrointestinal tract of the rat and pig. Biochim Biophys Acta 101:83-89, 1965

21. Yem DW, Wa HC: Purification and properties of $\beta-N$ acetylglucosaminidase from $E$. coli. J Bacteriol 125:324-331, 1976 


\section{BACTERIAL GLYCOSIDASES IN RAT CECUM}

22. Aminoff D, Furukawa K: Enzymes that destroy blood group specificity. I. Purification and properties of $\alpha$-L-fucosidase from Clostridium perfrigens. J Biol Chem 245:1659-1669, 1970

23. McGuire EF, Chipowsky S, Roseman S: $\beta-N$-Acetylgiucosaminidase, $\alpha-N$-acetylgalactosaminidase and $\beta$-galacto- sidase from Clostridium perfringens, Methods Enzymol 28:755-763, 1973

24. Hoogenraad JH, Hird FJR, White RG, Leng RA: Utilization of ${ }^{14} \mathrm{C}$-labeled Bacillus subtilis and Escherichia coli by sheep. Br J Nutr 24:129-144, 1970 